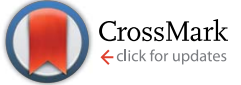

Cite this: DOI: 10.1039/c6ta07359j

\title{
Core-shell nano-structured carbon composites based on tannic acid for lithium-ion batteries $\uparrow$
}

\author{
Chenbo Liao, ${ }^{a}$ Qingkai Xu, ${ }^{a}$ Chaolumen Wu, ${ }^{a}$ Daling Fang, ${ }^{b}$ Shengyang Chen, ${ }^{a}$ \\ Shimou Chen, ${ }^{\star b}$ Jiangshui $\mathrm{LuO}^{\mathrm{C}}$ and Lei Li ${ }^{\star a d}$
}

Core-shell nano-structured carbon composites have been used as electrode materials in lithium-ion batteries (LIBs) with increasing attention. The large volume swing during lithiation/delithiation processes and poor electronic conductivity are two key issues in the newly-proposed electrode materials, which severely limit their practical applications in LIBs. In order to solve these problems, we report a facile and versatile method to prepare core-shell nano-structured carbon composites using low cost and widely available tannic acid as the carbon source. The carbon layers with controlled thicknesses of 6-12 nm and 1-3 nm were coated on the surface of $\mathrm{Si}$ and $\mathrm{TiO}_{2}$ nanoparticles, respectively. Due to the carbon layers, both the $\mathrm{SiaC}$ and $\mathrm{TiO}_{2} \mathrm{CC}$ nanocomposites used as anode materials in LIBs showed excellent electrochemical performances including good cycling stability and high rate capability. We believe that this method may be applicable to various carbon-coating nanocomposites.

Received 26th August 2016

DOI: 10.1039/c6ta07359j

www.rsc.org/MaterialsA

conductivity and $\mathrm{Li}^{+}$ion diffusion, $\mathrm{LiFePO}_{4} @ \mathrm{C}$ (cathode material) and $\mathrm{TiO}_{2} @ \mathrm{C}$ (anode material) core-shell nanocomposites were also developed for application in LIBs. ${ }^{\mathbf{9}, 10}$

The carbon shell can be prepared using various methods, such Core-shell nano-structured carbon composites have attracted considerable attention due to their potential applications in optics, catalysis, solar cells, fuel cells and lithium-ion batteries. ${ }^{1-3}$ In general, the core used as the major component is the nano-sized material with functional properties and the nanoscale carbon shell is used as a protection layer in order to (1) protect the core from outside environmental changes; (2) suppress core clustering and limit excessive particle growth; (3) restrict volume expansion and maintain structural integrity; and (4) improve, or bring new, physical or chemical properties. Due to these advantages, core-shell carbon nanocomposites have been widely used as electrode materials for lithium-ion batteries (LIBs) to overcome the disadvantages of nanomaterials and improve their general performance in LIBs. For example, Si@C, $\mathrm{Sn} @ \mathrm{C}, \mathrm{SnO}_{2} @ \mathrm{C}$ and $\mathrm{Co}_{3} \mathrm{O}_{4} @ \mathrm{CNT}$ core-shell nanocomposites used as anode materials showed excellent performance in LIBs since the carbon shell can offer an elastic buffering space for huge expansion/contraction. ${ }^{4-8}$ In order to improve electronic

${ }^{a}$ Shanghai Electrochemical Energy Devices Research Center, School of Chemistry and Chemical Engineering, Shanghai Jiaotong University, Shanghai 200240, China. E-mail: lilei0323@sjtu.edu.cn

${ }^{b}$ Key Laboratory of Green Process and Engineering, Institute of Process Engineering, Chinese Academy of Sciences, Beijing 100190, China. E-mail: chenshimou@ipe.ac.cn 'Department of Materials Engineering, KU Leuven, Leuven 3001, Belgium

${ }^{a}$ Shanghai Key Laboratory of Electrical Insulation and Thermal Aging, School of Chemistry and Chemical Engineering, Shanghai Jiaotong University, Shanghai 200240, China

$\dagger$ Electronic supplementary information (ESI) available. See DOI: as mechanical milling, hydrothermal or solvothermal synthesis, sol-gel process, and chemical vapor deposition (CVD) methods. ${ }^{11-14}$ However, these methods also suffer from one or more disadvantages due to their complex or multiple stages, rigorous reaction conditions or unstable precursors. For example, mechanical milling could not offer enough volume expansion accommodation and protection from outside erosion. The hydrothermal or solvothermal methods usually require extreme conditions, such as high temperature and high pressure. The CVD method normally needs special expensive equipment, which increases production costs. In addition, it is still a big challenge to coat a uniform and continuous carbon layer on the surface of nanoparticles based on these abovementioned methods. Recently, Wu's group reported some new methods to synthesize a uniform and controllable carbon coating on Si or metal oxides, including $\mathrm{SnO}_{2}$ and $\mathrm{CoO}$, through hydrothermal carbonization of cheap saccharides and simple pyrolysis of polyvinylidene fluoride (PVDF) or polypyrrole (PPy) conducting polymers. ${ }^{15-17}$

Recently, core-shell carbon nanocomposites based on dopamine as a carbon source were synthesized. ${ }^{18}$ However, this method is not suitable for practical applications since dopamine is too expensive. Herein, we report a simple and cheap method using a low-cost and widely-available carbon precursor, tannic acid (TA), to replace dopamine. TA is a type of plant polyphenol containing five digalloyl ester groups (see Scheme 1), which can be directly extracted from several natural plants such as tea, wood and oak. The cost of TA is much lower than that of 


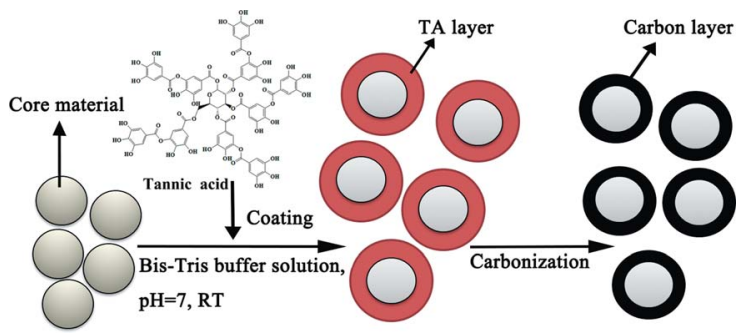

Scheme 1 Illustration of the preparation of core-shell nano-structured carbon composites using tannic acid as the carbon source.

dopamine. Similar to the polydopamine coating, the TA coating can also be formed spontaneously on virtually any surface in a bis-Tris buffer aqueous solution at room temperature. ${ }^{19,20}$ The thickness of the TA coating can be precisely controlled from 1 to tens of nanometers. ${ }^{19}$ The structural similarity of TA to phenolic resins prompted us to think that the TA coating should have a high carbon yield. To the best of our knowledge, however, the use of TA coating as a carbon precursor has never been reported. Considering silicon and titanium dioxide as two of the most promising anode materials for next-generation LIBs, we selected commercial Si nanoparticles (the diameter ranging from 30 to $100 \mathrm{~nm}$ ) and commercial anatase $\mathrm{TiO}_{2}$ nanoparticles (about $50 \mathrm{~nm}$ ) as the core materials in our experiments. Both $\mathrm{Si} @ \mathrm{C}$ and $\mathrm{TiO}_{2} @ \mathrm{C}$ nanoparticles with the controlled carbon layers were prepared by TA coating followed by carbonization. The morphologies, physical and electrochemical performance including discharge specific capacity, cycling stability and rate capability of these Si@C and $\mathrm{TiO}_{2} @ \mathrm{C}$ nanocomposites used as anodes in LIBs were investigated in our experiments.

\section{Experimental}

\section{Chemicals}

Silicon nanoparticles (the diameter ranging from 30 to $100 \mathrm{~nm}$ ) were purchased from Shanghai ST-Nano Science and Technology Co. Ltd. Anatase $\mathrm{TiO}_{2}$ nanoparticles (about $50 \mathrm{~nm}$ ), tannic acid (TA) and 2,2-bis(hydroxymethyl)-2,2',2"'-nitrilotriethanol (bis-Tris) were purchased from Aladdin Industrial Corporation. Battery-grade dimethyl carbonate (DMC), ethylene carbonate (EC) and $\mathrm{LiPF}_{6}$ were purchased from Shenzhen Capchem Chemicals Co., Ltd., and used without further purification. Liquid electrolyte of $1 \mathrm{M} \mathrm{LiPF}_{6}$ in a $1: 1$ (wt:wt) EC/ DMC solution used in our experiments was prepared in an argon-filled glove box, in which both oxygen and water content were less than $1 \mathrm{ppm}$.

\section{Synthesis of Si@C nanocomposites}

Typically, $180 \mathrm{mg}$ Si nanoparticles were dispersed in $100 \mathrm{~mL}$ bis-Tris buffer (100 mM buffer and $600 \mathrm{mM} \mathrm{NaCl})$ aqueous solution of tannic acid $\left(1.8 \mathrm{mg} \mathrm{mL}^{-1}, \mathrm{pH} 7.0\right)$ at room temperature. Afterwards, the precipitates were collected by centrifugation, washed with deionized water, and then dried at $80^{\circ} \mathrm{C}$ for $10 \mathrm{~h}$. To carbonize the tannic acid coating, the dried powders were placed in a tube and heated to $400{ }^{\circ} \mathrm{C}$ at a rate of $1{ }^{\circ} \mathrm{C}$ $\min ^{-1}$ under an Ar atmosphere and kept at this temperature for $2 \mathrm{~h}$, and then heated to $800^{\circ} \mathrm{C}$ with a heating rate of $5{ }^{\circ} \mathrm{C} \mathrm{min}-1$ and kept at $800{ }^{\circ} \mathrm{C}$ for $3 \mathrm{~h}$. In our experiments, Si@C nanocomposites were prepared with different polymerization times: 6 h for Si@C-1, 12 h for Si@C-2 and 24 h for Si@C-3.

\section{Synthesis of $\mathrm{TiO}_{2} @ \mathrm{C}$ nanocomposites}

Typically, $200 \mathrm{mg}$ anatase $\mathrm{TiO}_{2}$ nanoparticles were dispersed in $100 \mathrm{~mL}$ bis-Tris buffer (100 mM buffer and $600 \mathrm{mM} \mathrm{NaCl})$ aqueous solution of tannic acid $\left(2.0 \mathrm{mg} \mathrm{mL}^{-1}, \mathrm{pH} 7.0\right)$ at room temperature. Afterwards, the precipitates were collected by centrifugation, washed with deionized water, and then dried at $80{ }^{\circ} \mathrm{C}$ for $10 \mathrm{~h}$. To carbonize the tannic acid coating, the dried powders were placed in a tube and heated to $400{ }^{\circ} \mathrm{C}$ at a rate of $1{ }^{\circ} \mathrm{C} \mathrm{min}{ }^{-1}$ under an Ar atmosphere and kept at this temperature for $2 \mathrm{~h}$, then heated to $800{ }^{\circ} \mathrm{C}$ with a heating rate of $5{ }^{\circ} \mathrm{C} \mathrm{min}{ }^{-1}$ and kept at $800{ }^{\circ} \mathrm{C}$ for $3 \mathrm{~h}$. In our experiments, we prepared the $\mathrm{TiO}_{2} @ \mathrm{C}$ nanocomposites with different polymerization times: 6 $\mathrm{h}$ for $\mathrm{TiO}_{2} @ \mathrm{C}-1,12 \mathrm{~h}$ for $\mathrm{TiO}_{2} @ \mathrm{C}-2$ and $24 \mathrm{~h}$ for $\mathrm{TiO}_{2} @ \mathrm{C}-3$.

\section{Characterization}

Transmission electron microscopy (TEM) analysis was carried out with a JEM-2100 (JEOL Ltd., Japan) equipment operating at $200 \mathrm{kV}$. The chemical compositions of the tannic acid coated Si and $\mathrm{TiO}_{2}$ nanocomposites were analysed by Fourier transform infrared spectroscopy (ATR-FTIR, Spectrum 100, Perkin-Elmer, Inc., USA) and X-ray photoelectron spectroscopy (XPS) (Kratos Analytical-A Shimadzu Group Company), respectively. XPS measurements were carried out by a Kratos Axis UltraDLD spectrometer using a monochromatic $\mathrm{Al} \mathrm{K}_{\alpha}$ radiation $(h \nu=$ $1486.6 \mathrm{eV})$. The binding energies of the samples were calibrated by taking the carbon $1 \mathrm{~s}$ peak as a reference $(284.6 \mathrm{eV})$. The weight content of carbon in the $\mathrm{Si} @ \mathrm{C}$ and $\mathrm{TiO}_{2} @ \mathrm{C}$ nanocomposites were determined from the weight loss curve measured under simulated air atmosphere on a TG/DTA instrument (Perkin-Elmer) with a heating rate of $10{ }^{\circ} \mathrm{C} \mathrm{min}^{-1}$. Electronic conductivity of $\mathrm{TiO}_{2}$ and $\mathrm{TiO}_{2} @ \mathrm{C}$ nanocomposites was measured with the AC impedance method using an Autolab PGSTAT302 electrochemical test system (Eco Chemie, the Netherlands) at room temperature. The $\mathrm{TiO}_{2}$ and $\mathrm{TiO}_{2} @ \mathrm{C}$ nanocomposites pellets were prepared by pressing the corresponding powders at $20 \mathrm{MPa}$. The electronic conductivity was calculated from impedance data.

\section{In situ TEM measurement}

In situ TEM observations were conducted on a JEOL JEM-2100F equipped with a Nanofactory Instruments STM-TEM holder. In order to build up the test cell, the Si@C nanocomposites were immobilized on the surfaces of multi-walled carbon nanotubes, then attached to the gold rod, which was further attached to the piezo-manipulator. On the other side, a small piece of lithium foil was attached to a sharp-tip tungsten rod as a reference and counter electrode. The electrode was affixed to the TEM holder in an Ar-filled glove box and transported to the TEM. During this transfer process, the lithium foil was exposed to air and due to 
lithium being easily oxidized, the $\mathrm{Li}_{2} \mathrm{O}$ formed on the surface of the lithium foil can act as the solid electrolyte. Inside the TEM, the metallic probes can be spatially manipulated at the nanoscale, so that with the aid of the carbon nanotubes, the Si@C nanocomposites can come into electrical contact with the $\mathrm{Li}$ oxide layer coating the $\mathrm{Li}$ electrode, forming a nanobattery inside the TEM. In this experiment, the lithiation was carried out at a negative bias in the range from $-3 \mathrm{~V}$ to $0 \mathrm{~V}$ with respect to the Li metal.

\section{Electrochemical measurements}

Electrochemical properties of both $\mathrm{Si} @ \mathrm{C}$ and $\mathrm{TiO}_{2} @ \mathrm{C}$ nanocomposites were evaluated using CR2016 coin-type test cells. The working electrode was prepared by mixing $\mathrm{Si} @ \mathrm{C}$ or $\mathrm{TiO}_{2} @ \mathrm{C}$ nanocomposite, carbon black (Super P), and sodium carboxymethyl cellulose at a weight ratio of $70: 20: 10$, and casted onto copper foil. Lithium metal was used as the counter electrode and Celgard 2400 membrane was used as the separator. The electrolyte was $1 \mathrm{M} \mathrm{LiPF}_{6}$ in a $1: 1$ (wt : wt) EC/DMC solution. The test cells were assembled in an argon-filled glove box. The discharge-charge measurements were performed on a Land CT2001A tester (Wuhan, China) at room temperature. Electrochemical impedance spectroscopy (EIS) of the cell was observed immediately under fully charged condition. EIS measurements were accomplished by coupling the potentiostat with an Autolab frequency response analyzer locked in an amplifier and an impedance phase analyzer. A sinusoidal amplitude modulation was used over the frequency range from $0.1 \mathrm{~Hz}$ to $1 \mathrm{MHz}$. Cyclic voltammetry (CV) measurements of both pure nanoparticles and carbon nanocomposites were recorded on an Autolab PGSTAT302 electrochemical test system (Eco Chemie, the Netherlands) at room temperature. In our experiments, the CV measurements of both $\mathrm{TiO}_{2}$ and $\mathrm{TiO}_{2} @ \mathrm{C}$ electrodes were tested in the potential range of $0.005-3 \mathrm{~V}$ at a scan rate of $0.2 \mathrm{mV} \mathrm{s}^{-1}$, and the $\mathrm{CV}$ measurements of both $\mathrm{Si}$ and $\mathrm{Si@C} \mathrm{electrodes} \mathrm{were} \mathrm{tested} \mathrm{in} \mathrm{the} \mathrm{potential} \mathrm{range} \mathrm{of} 0.005-$ $1.5 \mathrm{~V}$ at a scan rate of $0.2 \mathrm{mV} \mathrm{s}^{-1}$.

\section{Results and discussion}

As shown in Scheme 1, the core-shell carbon nanocomposites were prepared through a two-step process. First, the TA coatings were spontaneously formed onto the surface of both $\mathrm{Si}$ and $\mathrm{TiO}_{2}$ nanoparticles in a bis-Tris buffer solution of $\mathrm{pH} 7.0$ in the presence of oxygen. And the color of both $\mathrm{Si}$ and $\mathrm{TiO} 2$ changed obviously after TA coating (see Fig. 1). The TA coatings on the surfaces of both $\mathrm{Si}$ and $\mathrm{TiO}_{2}$ nanoparticles were confirmed by FTIR measurements (see Fig. 2). It was found that the appearance of some new peaks, considered as the characteristic peaks of TA, included at $1708 \mathrm{~cm}^{-1}$ (the $\mathrm{C}=\mathrm{O}$ stretching vibration of the carboxylic acid group), $1564 \mathrm{~cm}^{-1}$ (the $\mathrm{C}=\mathrm{C}$ stretching vibration of the aromatic ring), ${ }^{22} 1504 \mathrm{~cm}^{-1}$ (the $\mathrm{C}-\mathrm{O}-\mathrm{H}$ inplane bend of the hydroxyl group), ${ }^{21} 1446 \mathrm{~cm}^{-1}$ and $1330 \mathrm{~cm}^{-1}$ (the $\mathrm{C}-\mathrm{O}$ stretching in the acid functionality in tannic acid), ${ }^{21}$ $1201 \mathrm{~cm}^{-1}$ (the $\mathrm{C}-\mathrm{O}$ stretching vibration of polyols), ${ }^{23,24}$ $875 \mathrm{~cm}^{-1}$ (the $\mathrm{C}-\mathrm{O}-\mathrm{C}$ bending mode), ${ }^{23,24}$ and $766 \mathrm{~cm}^{-1}$ (the
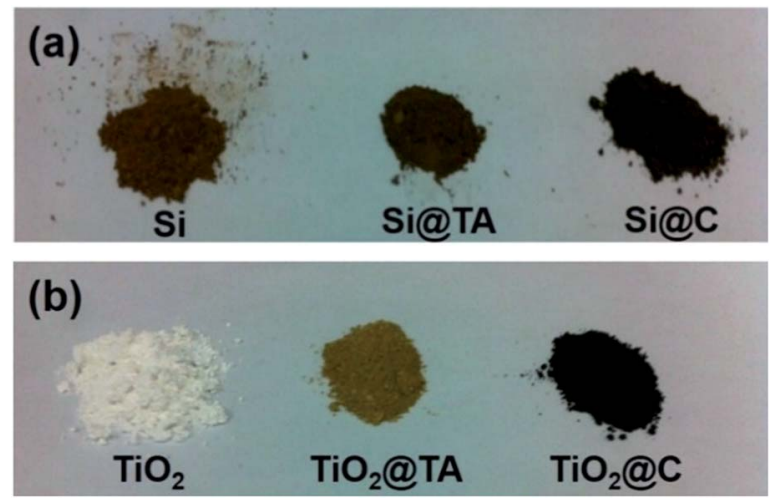

Fig. 1 Digital images of (a) Si, Si@TA and SiaC nanocomposites, and (b) $\mathrm{TiO}_{2}, \mathrm{TiO}_{2} \mathrm{QTA}$ and $\mathrm{TiO}_{2} @ \mathrm{CC}$ nanocomposites.

C-H out-of-plane bend of the phenyl group). ${ }^{23}$ Subsequently, the TA coatings were converted to carbon layers by carbonization in a nitrogen atmosphere at $800{ }^{\circ} \mathrm{C}$. Through this process, the core-shell Si@C and $\mathrm{TiO}_{2} @ \mathrm{C}$ nanocomposites were obtained, as shown in Fig. 4 and 5.

Lee et al. reported that dopamine molecules had strong adhesion to surfaces, and hypothesized that both catechol (DOPA) and amine (lysine) groups on the polydopamine may bind to surfaces through covalent and/or noncovalent interactions. ${ }^{25}$ From the chemical structure of tannic acid (see Scheme 1), we can observe that there are also some catechol groups present. In order to know the interaction between tannic acid and $\mathrm{Si}$ or $\mathrm{TiO}_{2}$ nanoparticles, X-ray photoelectron spectroscopy (XPS) measurements were carried out in our experiments.
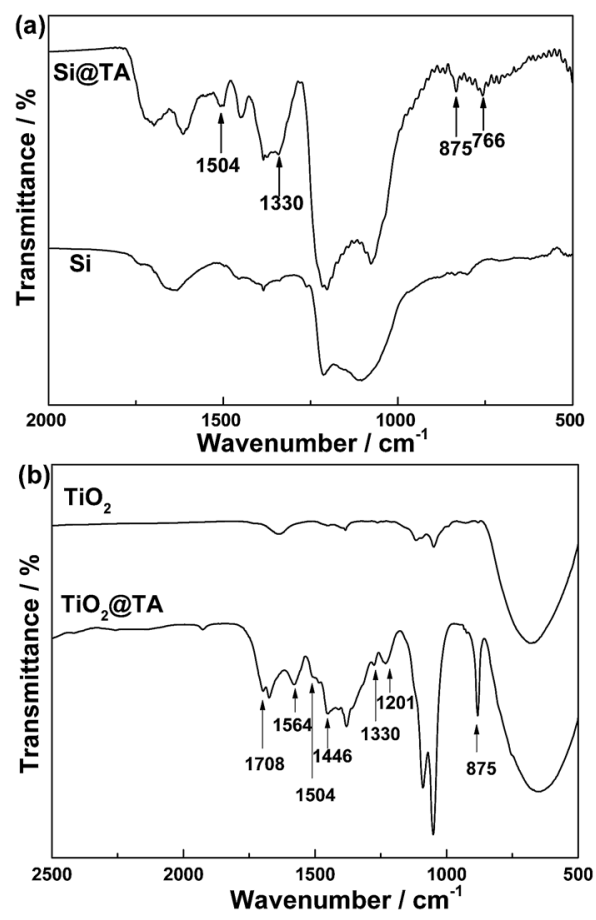

Fig. 2 FTIR spectra of (a) Si without and with the tannic acid coating, (b) $\mathrm{TiO}_{2}$ without and with the tannic acid coating. 
Fig. 3 shows $\mathrm{O} 1 \mathrm{~s}$ spectra of pure nanoparticles $\left(\mathrm{Si}\right.$ and $\left.\mathrm{TiO}_{2}\right)$ and $\mathrm{Si} @ \mathrm{C}$ and $\mathrm{TiO}_{2} @ \mathrm{C}$ nanocomposites. In the spectrum of $\mathrm{TiO}_{2}$ nanoparticles (see Fig. 3b), the main peak at the binding energy
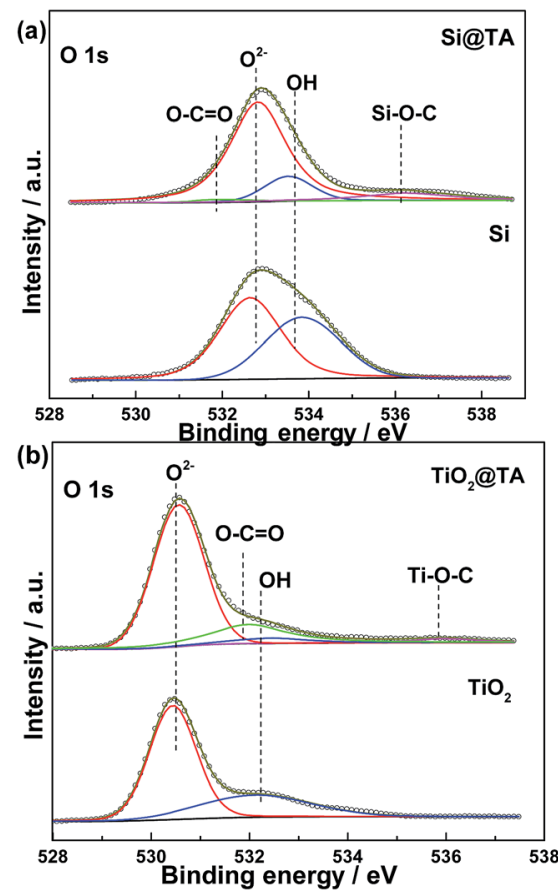

Fig. 3 XPS spectra of $\mathrm{O}$ 1s for (a) $\mathrm{Si}$ and $\mathrm{Si}$ (aTA samples, and (b) $\mathrm{TiO}_{2}$ and $\mathrm{TiO}_{2}$ (aTA samples.
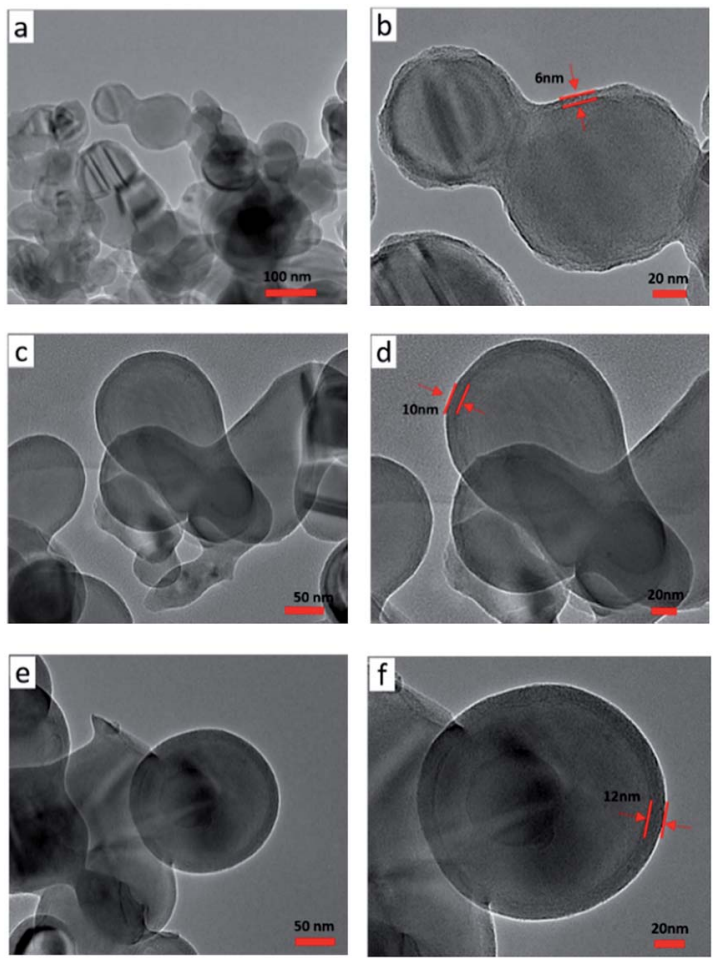

Fig. 4 TEM images of Si@C nanocomposites polymerized for (a) and (b) $6 \mathrm{~h}$, (c) and (d) $12 \mathrm{~h}$, and (e) and (f) $24 \mathrm{~h}$.
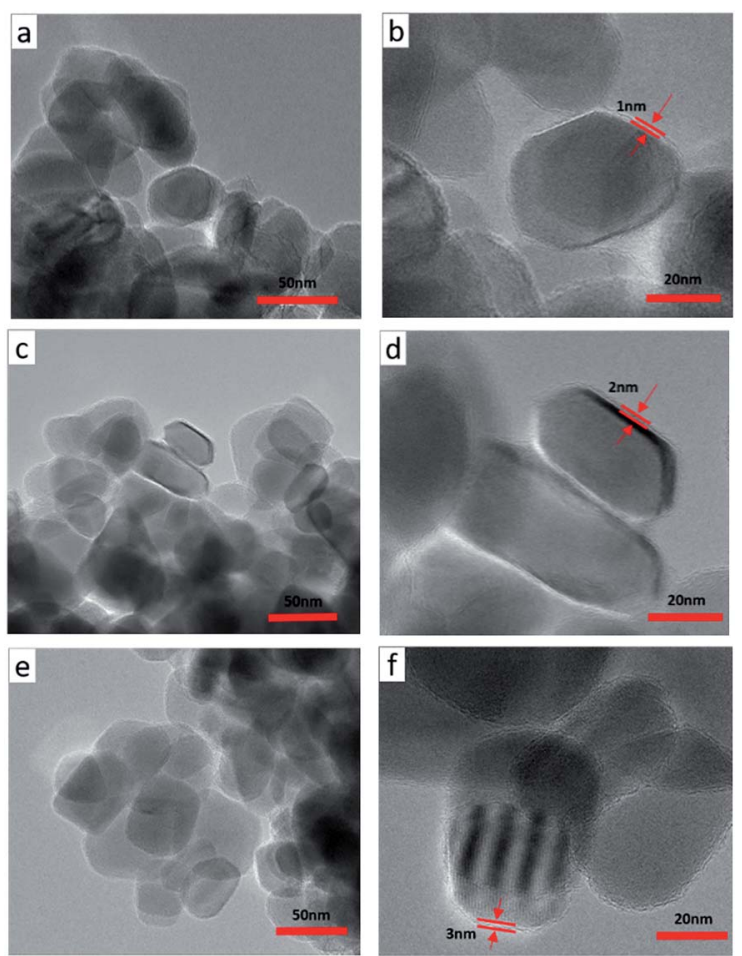

Fig. 5 TEM images of $\mathrm{TiO}_{2}$ @ $\mathrm{CC}$ nanocomposites for (a) and (b) $6 \mathrm{~h}$, (c) and (d) $12 \mathrm{~h}$, (e) and (f) $24 \mathrm{~h}$.

of $530.8 \mathrm{eV}$ is assigned to bulk oxide $\left(\mathrm{O}^{2-}\right)$, and the other peak, located at $532.2 \mathrm{eV}$, is assigned to hydroxyl $(\mathrm{OH}){ }^{26,27} \mathrm{The} \mathrm{OH}$ peak is considered to be from Ti-OH groups on the surface of the $\mathrm{TiO}_{2}$ nanoparticles. Compared with the pristine $\mathrm{TiO}_{2}$, there are two new peaks in the spectrum of $\mathrm{TiO}_{2} @ \mathrm{TA}$ : at $536.0 \mathrm{eV}$, assigned to the $\mathrm{O}-\mathrm{C}$, and at $531.8 \mathrm{eV}$, assigned to the $\mathrm{O}=\mathrm{C} .{ }^{28}$ These results indicate the success of coating $\mathrm{TA}$ on the $\mathrm{TiO}_{2}$ surface. In addition, the intensity of the Ti-OH peak was decreased compared with the pristine $\mathrm{TiO}_{2}$, which indicates the depletion of surface Ti-OH groups. Similar results about the depletion of surface Ti-OH groups after coating have been found in the coated $\mathrm{TiO}_{2}$ surfaces with low molecular weight catechols ${ }^{29}$ or mPEG-DOPA polymers. ${ }^{30}$ The possible mechanism for this may be the reaction between catechols and the Ti-OH surface, resulting in dehydration and the formation of a charge transfer complex. Similar results have been found in the spectra of Si and Si@C nanocomposites (see Fig. 3a). Compared with the pristine Si, two new peaks, at $536.4 \mathrm{eV}$ and $532.0 \mathrm{eV}$, appeared in the Si@TA spectrum which are attributed to $\mathrm{O}-\mathrm{C}$ and $\mathrm{O}=\mathrm{C}$ groups, respectively. And the intensity of the $\mathrm{Si}-\mathrm{OH}$ (at $533.8 \mathrm{eV}$ assigned to $\mathrm{OH}$ groups) peak is also lower than that of pristine $\mathrm{Si}$.

The thickness of carbon shell directly affects the electrochemical performance of both $\mathrm{Si}$ and $\mathrm{TiO}_{2}$ nanoparticles in the LIBs. When the carbon shell is too thin, it cannot restrict volume expansion during the charge-discharge process (for $\mathrm{Si}$ nanoparticles) and it is difficult to suppress the nano-sized cores clustering and limit excessive particle growth. When the carbon shell is too thick, however, it restricts the efficient ion transfer/transport. Therefore, it is important to obtain a carbon 
shell with an optimized thickness. In our experiments, the carbon shell thickness on the pristine $\mathrm{Si}$ and $\mathrm{TiO}_{2}$ nanoparticles will be controlled by the coating time. Fig. 4 and 5 show the Si@C and $\mathrm{TiO}_{2} @ \mathrm{C}$ nanocomposites with different coating times. It can be found that uniform and continuous carbon layers were coated on the surfaces of both $\mathrm{Si}$ and $\mathrm{TiO}_{2}$ nanoparticles. Since the Si commercial nanoparticles have some native oxides on the surface, we treated the Si@C nanocomposites in an $\mathrm{HF}$ aqueous solution to remove these native oxides. By varying the coating times, Si@C nanocomposites with different thicknesses of carbon shell were prepared: $\sim 6 \mathrm{~nm}$ for $6 \mathrm{~h}$ (Si@C-1), 10 nm for $12 \mathrm{~h}$ (Si@C-2) and $\sim 12 \mathrm{~nm}$ for $24 \mathrm{~h}$ (Si@C-3). The carbon contents, determined by thermogravimetric analysis (TGA-DTA), were about 7.6 wt\% (Si@C-1), 10.8 wt\% (Si@C-2) and 15.1 wt\% (Si@C-3). For the $\mathrm{TiO}_{2} @ \mathrm{C}$ nanocomposites, the thicknesses of carbon shells and carbon contents were $\sim 1 \mathrm{~nm}$ and $1.1 \mathrm{wt} \%$ for $6 \mathrm{~h}$ ( $\left.\mathrm{TiO}_{2} @ \mathrm{C}-1\right), \sim 2 \mathrm{~nm}$ and $1.9 \mathrm{wt} \%$ for $12 \mathrm{~h}\left(\mathrm{TiO}_{2} @ \mathrm{C}-2\right)$ and $\sim 3 \mathrm{~nm}$ and $3.0 \mathrm{wt} \%$ for 24 h ( $\left.\mathrm{TiO}_{2} @ \mathrm{C}-3\right)$ (Fig. 6).

Currently, the wide application of Si as an anode in LIBs is still impeded by the large volume expansion (up to 4 times) during the lithiation and delithiation which not only causes the pulverization of the electrode materials, but also leads to the delamination of the interface between the electrode material and the current collector, ultimately resulting in poor conductivity, cycling stability and rate capability of the batteries. ${ }^{3,31}$ To restrict the volume expansion of Si and maintain the structural integrity, a uniform and continuous carbon layer with a thickness of 6-12 nm was coated onto the Si nanoparticles. We used
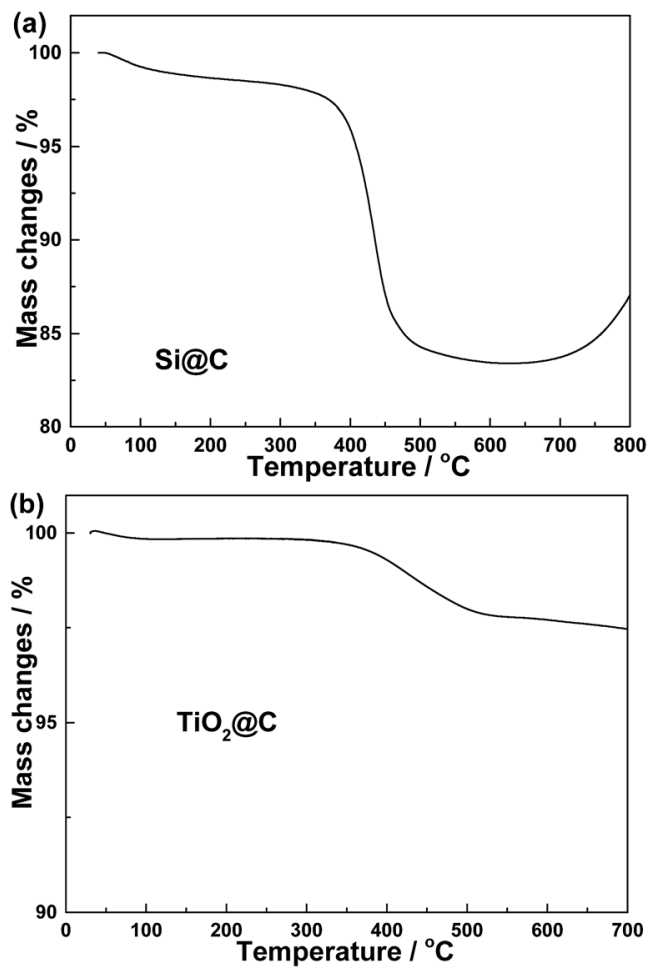

Fig. 6 Typical TG curves of (a) SiaC (24 h) and (b) $\mathrm{TiO}_{2} \mathrm{aC}(24 \mathrm{~h})$ nanocomposites. the in situ TEM technique to observe the deformation and structural changes of the Si@C nanocomposites during the lithiation/delithiation processes. Fig. 7a shows the TEM images of the nano lithium-ion battery used for in situ lithiation/delithiation tests. Fig. 7b-d shows a series of images taken from a movie of the in situ lithiation/delithiation tests for the Si@C nanocomposites (ESI, Movie S1 $\dagger$ ). In Fig. 7b (0 s, before lithiation), the Si nanoparticle is visible within a surrounding carbon shell and there is a very small void space, caused by the removal of the native oxides, which is not big enough to accommodate the expansion in volume of the Si nanoparticle between the Si core and the carbon shell. The Si nanoparticle expands in volume as Li diffuses through the carbon layer and alloys with $\mathrm{Si}$. The small void space between the core and shell disappeared after $11 \mathrm{~s}$, which demonstrates that the Si nanoparticle is partially lithiated (discharging). After $44 \mathrm{~s}$, the volume of the Si nanoparticle changes little, as seen from the TEM images, indicating that full lithiation is reached and no fracture of the carbon shell is observed after the lithiation of the Si nanoparticle. Fig. 7c shows the microstructure evolution during the delithiation (charging) of the Si@C nanocomposite. The gradual expansion of the space between the Si core and carbon shell shows the shrinkage of the Si nanoparticle as it is
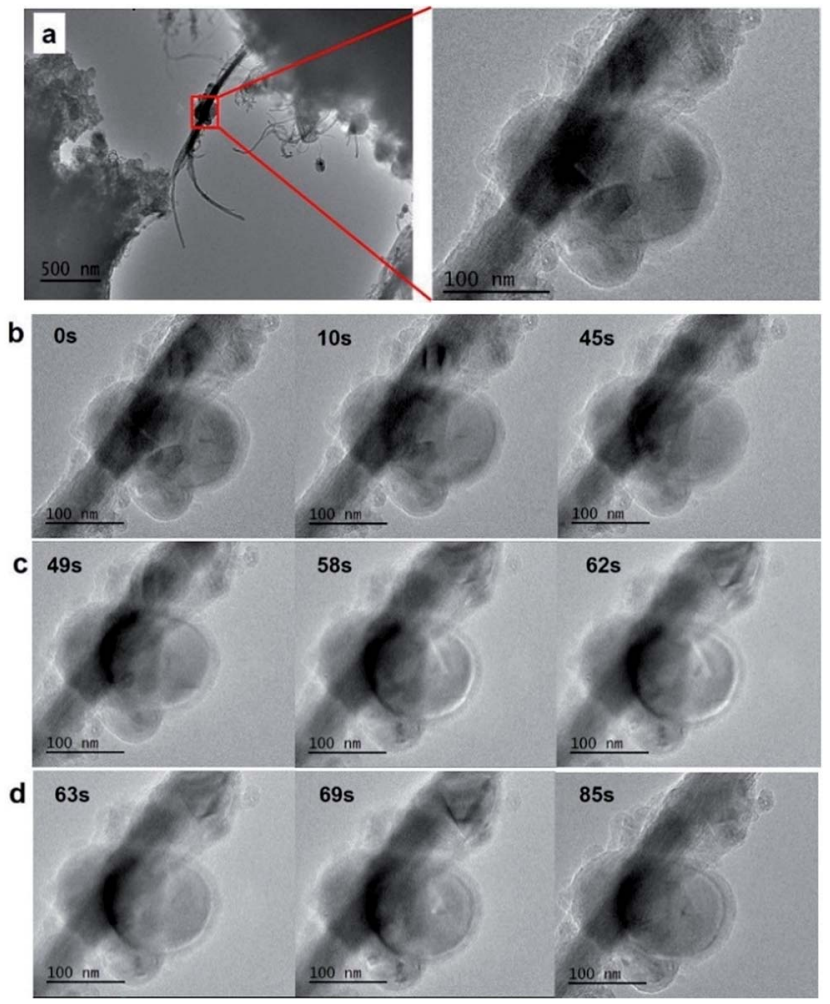

Fig. 7 (a) TEM image of the all-solid-state nano battery used for in situ lithiation/delithiation tests of the Si@C nanocomposites, where Li act as anode, $\mathrm{Li}_{2} \mathrm{O}$ as electrolyte and a carbon-coated Si nanoparticle adhering to a CNT as cathode. In situ TEM images of the microstructure evolution of the SiaC nanoparticle during (b) the lithiation, (c) delithiation and (d) relithiation. All the TEM images are taken from Movie S1 in the ESI. $\uparrow$ Note that the carbon shell did not rupture during the lithiation and delithiation processes. 
being charged. Fig. 7d shows the microstructure evolution of the Si@C nanocomposite during the relithiation (redischarging), and also we cannot observe any fracture of the carbon shell. These results indicate that the carbon shell is so robust that it can protect and accommodate large volume expansion of the Si nanoparticle during the lithiation, effectively preventing the battery anode from changing structurally upon cycling.

The first three cycles of CV curves of both pristine Si and Si@C nanocomposites are shown in Fig. 8 within a potential range of $0.005-1.5 \mathrm{~V}$ at a scan rate of $0.2 \mathrm{mV} \mathrm{s}^{-1}$. Both electrodes show typically Si-based cathodic and anodic peaks: the cathodic peaks at $0-0.4 \mathrm{~V}$ are attributable to the formation of $\mathrm{Li}_{x} \mathrm{Si}$ alloys, and the corresponding anodic peaks at around $0.37 \mathrm{~V}$ and $0.55 \mathrm{~V}$ are related to the delithiation process of Li-Si alloys. ${ }^{17,32}$ It is also observed that the intensity of anodic peaks for both electrodes enhanced in the first three cycles, which maybe due to the activation processes of Si electrodes. ${ }^{17}$

The cycling stability and specific capacity of LIBs will be directly affected by the carbon layer thickness of the Si@C nanocomposite. If the carbon layer is too thin, it is hard to protect and accommodate large volume expansion of Si cores during charging-discharging processes. To investigate the optimal thickness of carbon layers in the Si@C nanocomposites as anodes in the LIBs, we prepared Si@C nanocomposites with different thicknesses of carbon layers. Since the carbon layer is also lithiated as observed in the in situ TEM experiments (see Movie S1 in the ESI $\dagger$ ), both the carbon shell and $\mathrm{Si} / \mathrm{TiO}_{2}$ core are contributing to the specific capacity. Therefore, the specific capacity values reported in our experiments are calculated on the basis of the total weight of both $\mathrm{Si} @ \mathrm{C}$ and $\mathrm{TiO}_{2} @ \mathrm{C}$ nanocomposites. The cycling performance of the pristine $\mathrm{Si}$ and all
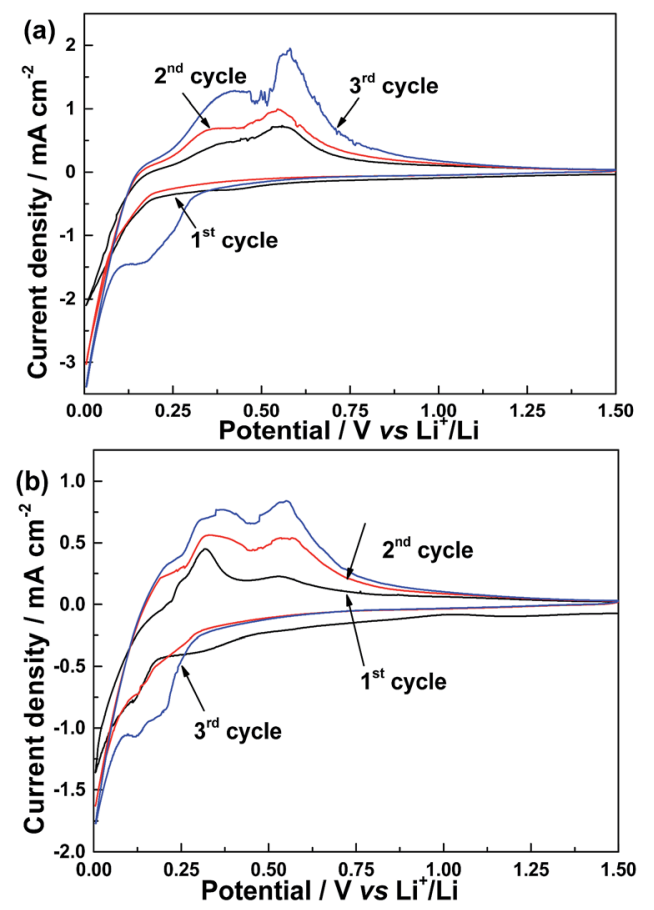

Fig. 8 Cyclic voltammogram curves of pristine (a) Si and (b) Si@C at a scan rate of $0.2 \mathrm{mV} \mathrm{s}^{-1}$ and at room temperature.
Si@C anodes in the LIBs are shown in Fig. 9a. For the cycling test, the cell was cycled at a rate of $0.1 \mathrm{~A} \mathrm{~g}^{-1}$ for one cycle, then $0.5 \mathrm{~A} \mathrm{~g}^{-1}$ for 3 cycles and $1 \mathrm{~A} \mathrm{~g}^{-1}$ for the later cycles. It was found that the specific capacity of the pristine $\mathrm{Si}$ anode rapidly decreased to less than $500 \mathrm{~mA} \mathrm{~h} \mathrm{~g}{ }^{-1}$ after 10 cycles due to the large volume expansion of Si during the lithiation and delithiation. Thanks to the protective effect from the carbon shells, all Si@C nanocomposites show much better cycling stability than that of the pristine Si anode. After 200 cycles, the specific capacity of all Si@C anodes is above $700 \mathrm{~mA} \mathrm{~h} \mathrm{~g}^{-1}$. The Si@C-3 anode (which declined from $1121.6 \mathrm{~mA} \mathrm{~h} \mathrm{~g}^{-1}$ to $1019.1 \mathrm{~mA} \mathrm{~h} \mathrm{~g}^{-1}$ after 200 cycles at $1 \mathrm{~A} \mathrm{~g}^{-1}$ ) shows the highest cycling performance, higher than both Si@C-1 (declining from 1219.4 $\mathrm{mA} \mathrm{h} \mathrm{g}{ }^{-1}$ to $764.2 \mathrm{~mA} \mathrm{~h} \mathrm{~g}{ }^{-1}$ after 200 cycles at $1 \mathrm{~A} \mathrm{~g}^{-1}$ ) and Si@C-2 (declining from $1180.4 \mathrm{~mA} \mathrm{~h} \mathrm{~g}^{-1}$ to $844.5 \mathrm{~mA} \mathrm{~h} \mathrm{~g}^{-1}$ after 200 cycles at $1 \mathrm{~A} \mathrm{~g}^{-1}$ ) anodes due to the different thicknesses of carbon shells in the Si@C nanocomposites. Nyquist plots obtained from EIS measurements of all the pristine Si and Si@C electrodes are shown in Fig. 9b, and the equivalent circuit for this cell system is depicted, in which $R_{\mathrm{S}}$ is ohmic resistance of the electrolyte and cell components, $R_{\mathrm{ct}}$ is the charge transfer resistance, CPE is a constant phase element and $W_{\mathrm{f}}$ is the Warburg impedance. ${ }^{32,33}$ The semicircular arc at the highfrequency region is related to the $R_{\text {ct }}$ value. According to the fitted results, the values of charge transfer resistance for $\mathrm{Si}$, Si@C-1, Si@C-2 and Si@C-3 anodes are 276.3 $\Omega, 204.2 \Omega, 127.6$ $\Omega$ and $91.2 \Omega$, respectively, and $\mathrm{Si} @ \mathrm{C}-3$ shows the lowest transfer resistance value among all anode materials, indicating the best electron/ion transfer kinetics of the Si@C-3 anode with
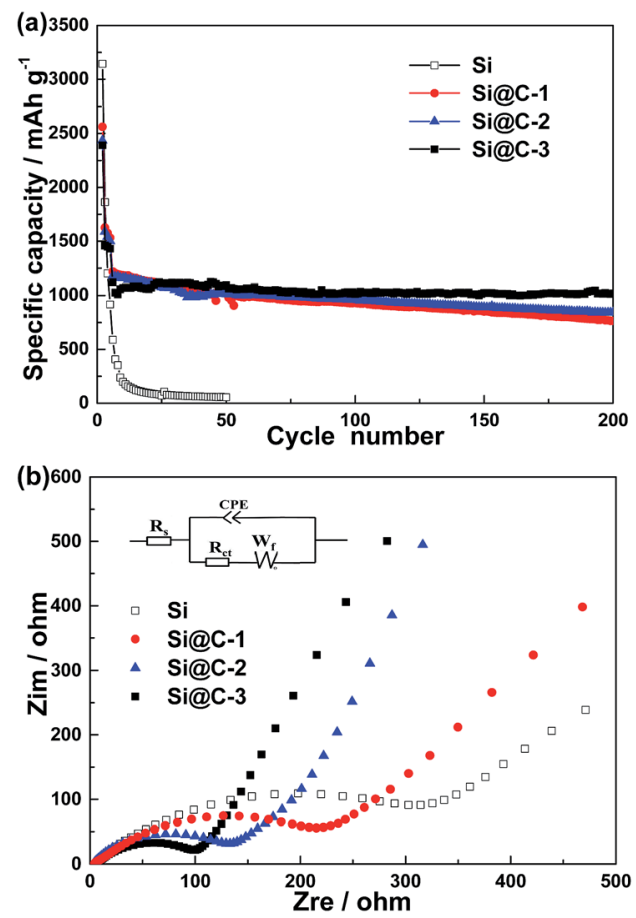

Fig. 9 (a) Discharge capacity versus cycle number plots of Si and SiaC nanocomposites. The rate was $0.1 \mathrm{~A} \mathrm{~g}^{-1}$ for one cycle, then $0.5 \mathrm{~A} \mathrm{~g}^{-1}$ for 3 cycles and $1 \mathrm{~A} \mathrm{~g}^{-1}$ for the later cycles. (b) Nyquist plots of $\mathrm{Si}$ and Si@C electrodes. 
respect to the lithiation/delithiation process, which will be favorable for the electrochemical performance of a lithium-ion battery.

Since the Si@C-3 nanocomposites show good cycling stability and electron/ion transfer kinetic properties among all the Si@C nanocomposites, we systematically studied the electrochemical performance of the Si@C-3 nanocomposites in the LIBs, including their long-term cycle stability and rate capability. As shown in Fig. 10a, there is no clear capacity decay observed in the first 300 cycles, and the capacity retention value after 500 cycles was about $93.1 \%\left(\sim 1000 \mathrm{~mA} \mathrm{~h} \mathrm{~g}^{-1}\right)$. The voltage profiles for the different cycles are shown in Fig. 10b. The shape of the profile does not change from the $25^{\text {th }}$ to $500^{\text {th }}$ cycle, indicating the stable electrochemical behavior of the Si@C nanocomposites. The Si@C core-shell structure is still well preserved after 500 cycles, as shown in the TEM image in Fig. 10c. In addition, the battery using the Si@C-3 nanocomposite as anode also showed good rate capability (Fig. 10d). Even at a rate of $10 \mathrm{~A} \mathrm{~g}^{-1}$, the Si@C electrode can still show a specific capacity of $580 \mathrm{~mA} \mathrm{~h} \mathrm{~g}^{-1}$, which is much higher than that of the theoretical specific capacity of graphite. Several current literatures have reported that the core-shell structure of Si@C nanocomposites improves the performance of Si-based anodes in lithium-ion batteries. For example, Ji et al. prepared NG/Si@NC composite, which exhibited an initial reversible capacity of $1142 \mathrm{~mA} \mathrm{~h} \mathrm{~g}^{-1}$ at a current density of $500 \mathrm{~mA} \mathrm{~g}^{-1}$ and remained at $938 \mathrm{~mA} \mathrm{~h} \mathrm{~g}^{-1}$ after 100 cycles with an $82 \%$ retention. ${ }^{34}$ Li et al. prepared a core-shell structured graphite/silicon@pyrolyzed-carbon (G/Si@C) composite which showed a reversible capacity of $637.7 \mathrm{~mA} \mathrm{~h} \mathrm{~g}^{-1}$ and capacity retention of $89.5 \%$ after 100 cycles. $^{35}$ Li et al. ${ }^{36}$ prepared hollow core-shell structured porous $\mathrm{Si}-\mathrm{C}$ nanocomposites, which showed $650 \mathrm{~mA}$ $\mathrm{h} \mathrm{g}^{-1}$ at $1 \mathrm{~A} \mathrm{~g}^{-1}$ after 100 cycles, and about $350 \mathrm{~mA} \mathrm{~h} \mathrm{~g}{ }^{-1}$ at the rate of $8 \mathrm{~A} \mathrm{~g}^{-1}$. Compared with the abovementioned researches, our Si@C electrode shows much better cycling performance and higher rate performance which is contributed by the uniform, continuous, robust and optimized thickness of carbon shell on the Si nanoparticles. Since the carbon layer is robust enough to restrain the large volume expansion of the Si anode, the SEI would not be ruptured during the charging-discharging processes.

The practical application of $\mathrm{TiO}_{2}$ used as a typically safe anode material in LIBs is still hindered due to its low electronic conductivity, finally resulting in low specific capacity and poor cycling performance of batteries..$^{37,38}$ To solve this problem, a uniform and continuous carbon layer with about 1-3 nm was coated on the surface of the $\mathrm{TiO}_{2}$ nanoparticles. $\mathrm{TiO}_{2} @ \mathrm{C}$ nanocomposites with different thicknesses of carbon layer can be obtained by varying the polymerization time: $6 \mathrm{~h}$ for $\mathrm{TiO}_{2} @ \mathrm{C}$ 1 ( 1 nm), $12 \mathrm{~h}$ for $\mathrm{TiO}_{2} @ \mathrm{C}-2(\sim 2 \mathrm{~nm})$ and $24 \mathrm{~h}$ for $\mathrm{TiO}_{2} @ \mathrm{C}-3$ $(\sim 3 \mathrm{~nm})$ (Fig. 5). The electronic conductivity improved because the carbon was coated on the surface of $\mathrm{TiO}_{2}$. The electronic conductivity of $\mathrm{TiO}_{2}, \mathrm{TiO}_{2} @ \mathrm{C}-1, \mathrm{TiO}_{2} @ \mathrm{C}-2$ and $\mathrm{TiO}_{2} @ \mathrm{C}-3$ was $2.66 \times 10^{-5} \mathrm{~S} \mathrm{~cm}^{-1}, 9.56 \times 10^{-5} \mathrm{~S} \mathrm{~cm}^{-1}, 9.13 \times 10^{-5} \mathrm{~S} \mathrm{~cm}^{-1}$ and $1.34 \times 10^{-4} \mathrm{~S} \mathrm{~cm}^{-1}$, respectively.

Cyclic voltammograms of both the pristine $\mathrm{TiO}_{2}$ and $\mathrm{TiO}_{2} @ \mathrm{C}$ for the first three cycles at a rate of $0.2 \mathrm{mV} \mathrm{s}^{-1}$ within a potential
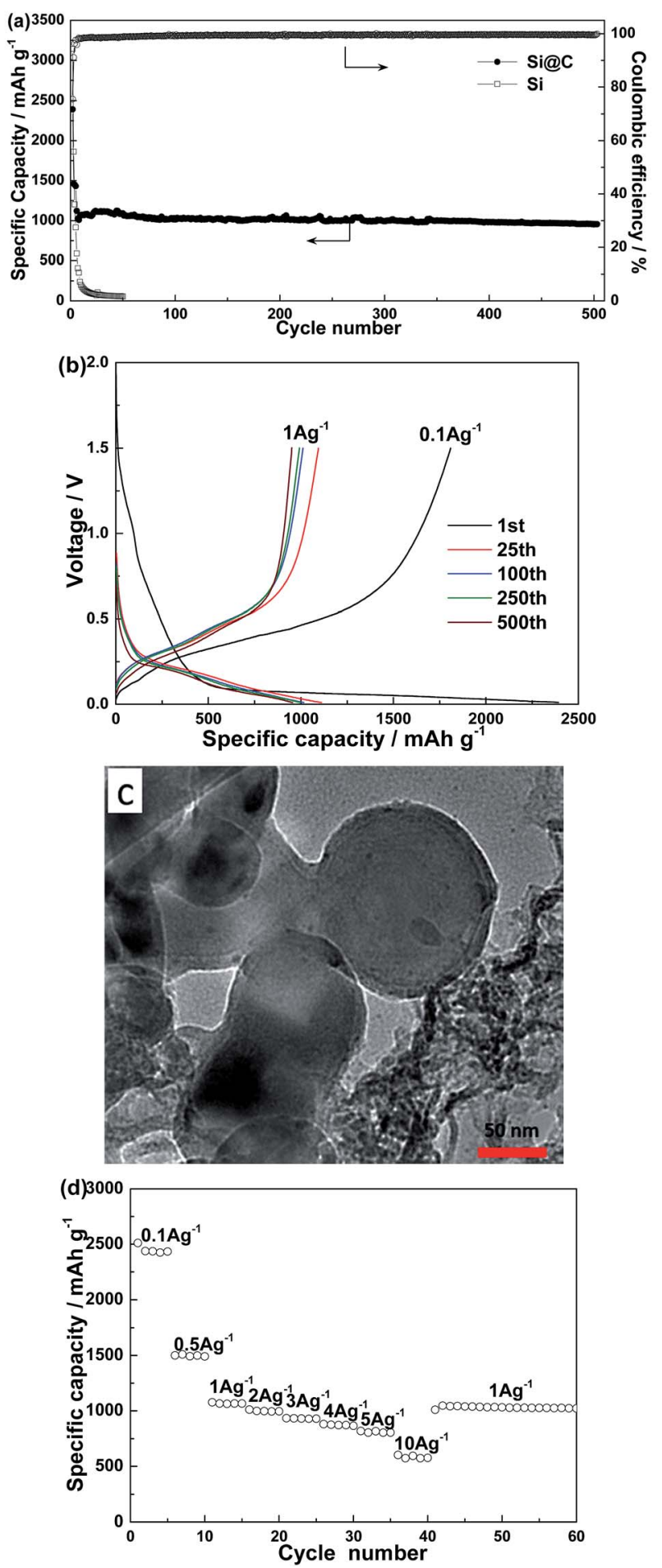

Fig. 10 Electrochemical performance of Si@C electrode in lithiumion battery. (a) Discharge-capacity and CE versus cycle number plots of Si@C and Si nanoparticles as anodes. The rate was $0.1 \mathrm{~A} \mathrm{~g}^{-1}$ for one cycle, then $0.5 \mathrm{~A} \mathrm{~g}^{-1}$ for 3 cycles and $1 \mathrm{~A} \mathrm{~g}^{-1}$ for the later cycles. (b) Voltage profiles plotted for the first, 25th, 100th, 250th and 500th cycles. (c) TEM images of SiaC electrode after 500 cycles showing the Siac core-shell structures still well resolved. (d) Rate capability of SiaC electrode. 
range from 0.005 to $3.0 \mathrm{~V}$ are shown in Fig. 11. Two main current peaks are observed at about $1.75 \mathrm{~V}$ and $2.1 \mathrm{~V}$ during cathodic and anodic sweeps, which correspond to the lithiation and delithiation of $\mathrm{Li}_{x} \mathrm{TiO}_{2} \cdot{ }^{39,40}$ The peak at $0.6 \mathrm{~V}$ of $\mathrm{TiO}_{2} @ \mathrm{C}$ at the first lithiation process contributes to the formation of SEI. The oxidation peak at $2.35 \mathrm{~V}$ of $\mathrm{TiO}_{2}$ @C in the first cycle declined rapidly during the subsequent cycling process, which may be ascribed to irreversible oxidation of the electrolyte or organic impurities. ${ }^{38}$

The electrochemical performance of the $\mathrm{TiO}_{2} @ \mathrm{C}$ nanocomposite was improved (Fig. 12). The voltage profiles of the first cycle at $\mathrm{C} / 10$ rate of the electrodes based on $\mathrm{TiO}_{2}$ and $\mathrm{TiO}_{2} @ \mathrm{C}$ nanocomposite are shown in Fig. 12a. Both the electrodes show the characteristic features of anatase $\mathrm{TiO}_{2}$ upon lithiation (discharge) and subsequent delithiation (charge). The performance of the first cycle of the battery with the $\mathrm{TiO}_{2}$ @C anode (charge capacity: $233.1 \mathrm{~mA} \mathrm{~h} \mathrm{~g}^{-1}$, discharge capacity: $253.3 \mathrm{~mA} \mathrm{~h} \mathrm{~g}^{-1}$, coulombic efficiency: $92.0 \%$ ) was better than that of the battery with the pristine $\mathrm{TiO}_{2}$ anode (charge capacity: $187.7 \mathrm{~mA} \mathrm{~h} \mathrm{~g}^{-1}$, discharge capacity: $222.9 \mathrm{~mA} \mathrm{~h} \mathrm{~g}^{-1}$, coulombic efficiency: $84.2 \%$ ). Fig. 12b shows the cycling performance of the pristine $\mathrm{TiO}_{2}$ and all $\mathrm{TiO}_{2}$ @C anodes at a current density of $0.5 \mathrm{C}$ between 1.0 and $3.0 \mathrm{~V}$. It can be found that the electrochemical performance of the $\mathrm{TiO}_{2} @ \mathrm{C}$ electrode was better than that of the pristine $\mathrm{TiO}_{2}$ electrode. The first cycle discharge capacities of the pristine $\mathrm{TiO}_{2}, \mathrm{TiO}_{2} @ \mathrm{C}-1, \mathrm{TiO}_{2} @ \mathrm{C}-2$ and $\mathrm{TiO}_{2} @ \mathrm{C}-3$ electrodes were about $147.5 \mathrm{~mA} \mathrm{~h} \mathrm{~g}{ }^{-1}, 162.3 \mathrm{~mA} \mathrm{~h}$ $\mathrm{g}^{-1}, 165.6 \mathrm{~mA} \mathrm{~h} \mathrm{~g}^{-1}$ and $167.4 \mathrm{~mA} \mathrm{~h} \mathrm{~g}^{-1}$, respectively. It can be found that the capacity of the $\mathrm{TiO}_{2} @ \mathrm{C}$ electrode was higher
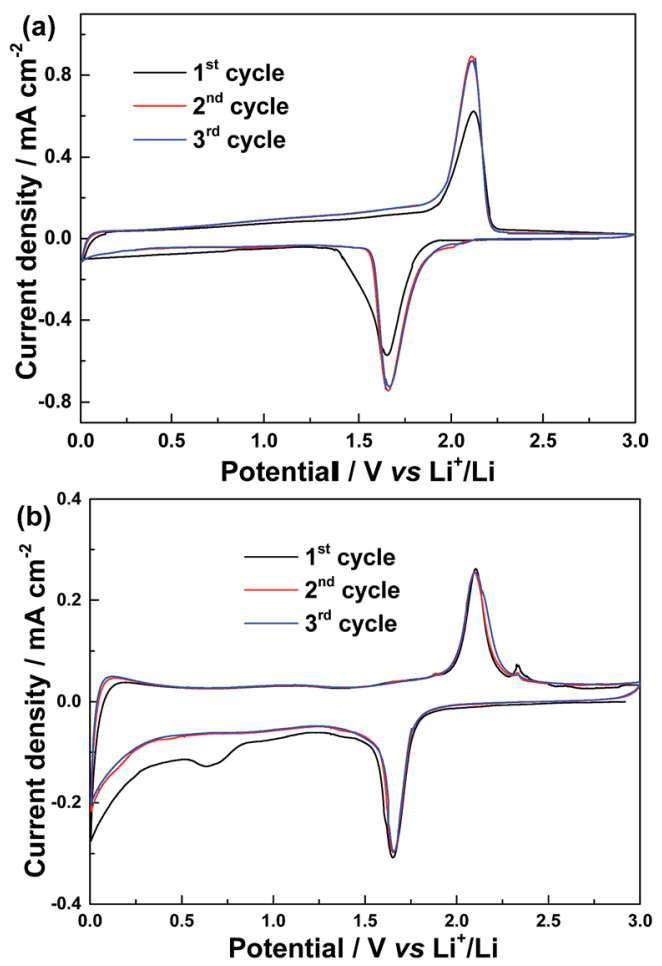

Fig. 11 Cyclic voltammogram curves of pristine (a) $\mathrm{TiO}_{2}$ and (b) $\mathrm{TiO}_{2} \mathrm{QC}$ at a scan rate of $0.2 \mathrm{mV} \mathrm{s}^{-1}$ and at room temperature.
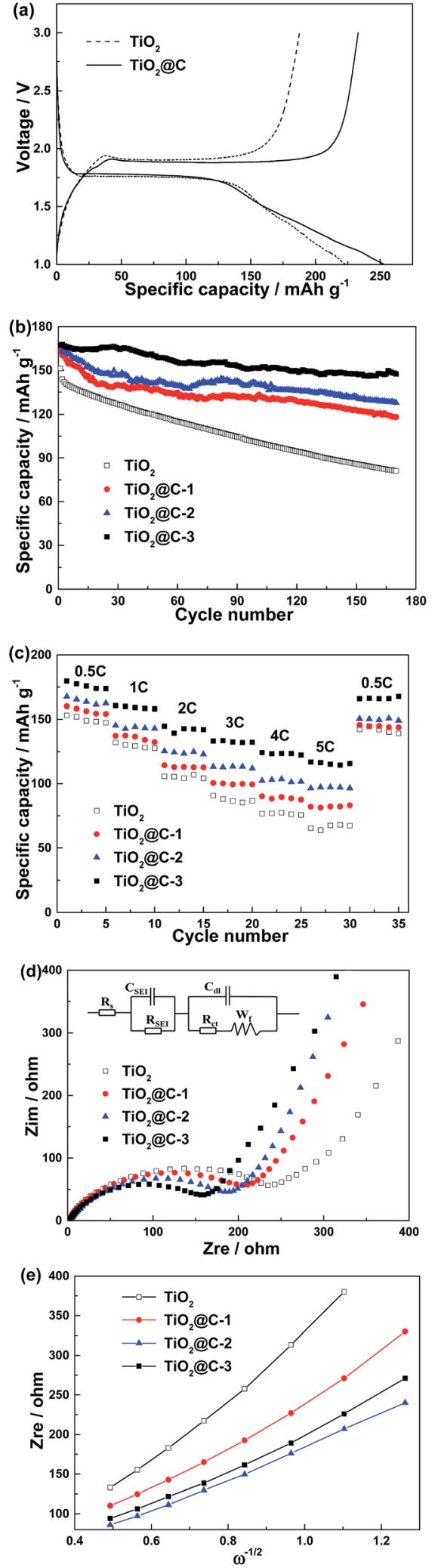

Fig. 12 Electrochemical performance of $\mathrm{TiO}_{2} @ \mathrm{CC}$ electrode in lithiumion battery. (a) Voltage profiles of $\mathrm{TiO}_{2}$ and $\mathrm{TiO}_{2} \mathrm{aC}$ electrodes during the first cycle at $0.1 \mathrm{C}$. (b) Discharge capacity versus cycle number plots of $\mathrm{TiO}_{2}$ and $\mathrm{TiO}_{2} \mathrm{QC}$ electrodes. Rate: 0.5C. (c) Rate capability of $\mathrm{TiO}_{2}$ and $\mathrm{TiO}_{2} \mathrm{aC}$ electrodes. (d) and (e) Nyquist plots of $\mathrm{TiO}_{2}$ and $\mathrm{TiO}_{2} \mathrm{aC}$ electrodes after 170 th cycle at $0.5 \mathrm{C}$. 
than that of the pristine $\mathrm{TiO}_{2}$ electrode due to the carbon coated onto the $\mathrm{TiO}_{2}$ nanoparticles. The cycling performance of the pristine $\mathrm{TiO}_{2}$ electrode was very poor and the capacity declined to about $81.1 \mathrm{~mA} \mathrm{~h} \mathrm{~g}^{-1}$ (53.6\% of the first cycle capacity) after the $170^{\text {th }}$ cycle. In contrast, the $\mathrm{TiO}_{2} @ \mathrm{C}$ electrode showed excellent cycling stability. After 170 cycles, the capacity loss was about 27.2\% (about $118.1 \mathrm{~mA} \mathrm{~h} \mathrm{~g}^{-1}$ ), 22.8\% (about $127.9 \mathrm{~mA}$ $\mathrm{h} \mathrm{g}^{-1}$ ) and $11.9 \%$ (about $147.5 \mathrm{~mA} \mathrm{~h} \mathrm{~g}{ }^{-1}$ ) for $\mathrm{TiO}_{2} @ \mathrm{C}-1$, $\mathrm{TiO}_{2} @ \mathrm{C}-2$ and $\mathrm{TiO}_{2} @ \mathrm{C}-3$ electrodes, respectively. In addition, the $\mathrm{TiO}_{2} @ \mathrm{C}$ electrode showed higher rate capability than that of the pristine $\mathrm{TiO}_{2}$ electrode at different rates, as shown in Fig. 12c. It can be found that the $\mathrm{TiO}_{2} @ \mathrm{C}-3$ anode with about a $3 \mathrm{~nm}$ thick carbon shell shows the best cycling stability, highest specific capacity and best rate capability among all the $\mathrm{TiO}_{2} @ \mathrm{C}$ nanocomposites.

Due to the presence of the uniform carbon coating layer, the $\mathrm{TiO}_{2} @ \mathrm{C}$ electrode exhibited lower resistance than that of the pristine $\mathrm{TiO}_{2}$ electrode as shown by the reduced diameter of the semicircle at the high-frequency region and the appreciably steep slope line at the low-frequency region in the electrochemical impedance spectroscopy (EIS) (Fig. 12d). Nyquist plots obtained from EIS measurements of the pristine $\mathrm{TiO}_{2}$ and $\mathrm{TiO}_{2} @ \mathrm{C}$ electrodes after 170 cycles are shown in Fig. $12 \mathrm{~d}$ and e. The values of charge transfer resistance $\left(R_{\mathrm{ct}}\right)$ for $\mathrm{TiO}_{2}, \mathrm{TiO}_{2} @ \mathrm{C}-$ 1, $\mathrm{TiO}_{2} @ \mathrm{C}-2$ and $\mathrm{TiO}_{2} @ \mathrm{C}-3$ are $230.5 \Omega, 187.6 \Omega, 179.1 \Omega$, and $130.7 \Omega$, respectively. The $R_{\mathrm{ct}}$ values of all $\mathrm{TiO}_{2} @ \mathrm{C}$ nanocomposites are smaller than that of the pristine $\mathrm{TiO}_{2}$. The value of $R_{\mathrm{ct}}$ was in the order: $\mathrm{TiO}_{2} @ \mathrm{C}-3<\mathrm{TiO}_{2} @ \mathrm{C}-2<\mathrm{TiO}_{2} @ \mathrm{C}-1<$ $\mathrm{TiO}_{2}$. The diffusion coefficient $D$ of the lithium ion can be calculated from plots in the low-frequency region according to the following equation: ${ }^{39}$

$$
D=R^{2} T^{2} / 2 A^{2} n^{4} F^{4} C^{2} \sigma^{2}
$$

$\sigma$ is the Warburg factor which has the relationship with $Z_{\mathrm{re}}$ as follows: ${ }^{41}$

$$
Z_{\mathrm{re}}=R_{\mathrm{ct}}+R_{\mathrm{s}}+\sigma \omega^{-1 / 2}
$$

Based on eqn (1) and (2), the values of the diffusion coefficients of $\mathrm{TiO}_{2}, \mathrm{TiO}_{2} @ \mathrm{C}-1, \mathrm{TiO}_{2} @ \mathrm{C}-2$ and $\mathrm{TiO}_{2} @ \mathrm{C}-3$ are $5 \times$ $10^{-13} \mathrm{~cm}^{2} \mathrm{~s}^{-1}, 1.07 \times 10^{-12} \mathrm{~cm}^{2} \mathrm{~s}^{-1}, 1.45 \times 10^{-12} \mathrm{~cm}^{2} \mathrm{~s}^{-1}$ and $1.27 \times 10^{-12} \mathrm{~cm}^{2} \mathrm{~s}^{-1}$, respectively. Compared with the pristine $\mathrm{TiO}_{2}$, the $\mathrm{TiO}_{2} @ \mathrm{C}$ nanocomposites show a higher $\mathrm{Li}^{+}$ion diffusion ability. The value of the diffusion coefficient of $\mathrm{Li}^{+}$ ion was in the order: $\mathrm{TiO}_{2} @ \mathrm{C}-2>\mathrm{TiO}_{2} @ \mathrm{C}-3>\mathrm{TiO}_{2} @ \mathrm{C}-1>$ $\mathrm{TiO}_{2}$. The results of the EIS confirm the improvement of the electronic conductivity and ion permeability of the carbon shell, which will be favorable for the electrochemical performance of the lithium-ion battery during cycling. Among all $\mathrm{TiO}_{2} @ \mathrm{C}$ nanocomposites, the $\mathrm{TiO}_{2} @ \mathrm{C}-3$ shows the best cycling performance, which was also confirmed by the EIS result. Although the value of diffusion coefficient of $\mathrm{TiO}_{2} @ \mathrm{C}-3$ is a little lower than that of $\mathrm{TiO}_{2} @ \mathrm{C}-2$, the lower $R_{\mathrm{ct}}$ and the thicker carbon layer that can suppress the volume change, which finally results in making the $\mathrm{TiO}_{2} @ \mathrm{C}-3$ electrode have the better cycling performance.

\section{Conclusions}

In conclusion, we developed a versatile and cheap method to synthesize core-shell carbon nanocomposites using tannic acid as the carbon source. The uniform and continuous carbon layers with a controlled thickness on the surface of the Si and $\mathrm{TiO}_{2}$ nanoparticles were obtained easily by a simple immersion of both nanoparticles in a tannic acid aqueous solution and subsequent carbonization. Due to the carbon shells, both Si@C and $\mathrm{TiO}_{2} @ \mathrm{C}$ nanocomposites used as anode materials in lithium-ion batteries showed excellent electrochemical performance, such as higher specific capacity, better cycling stability and higher rate capability. We expect that this coating method may be utilized in the construction of various nano-structured carbon-based materials, such as core-shell, yolk-shell, rattletype, and hollow carbon nanospheres or capsules.

\section{Acknowledgements}

This research was supported by Natural Science Foundation of Shanghai (14ZR1422100), Science and Technology Commission of Shanghai Municipality (14DZ2250800). Thanks to the Instrumental Analysis Center of Shanghai Jiaotong University.

\section{Notes and references}

1 F. Caruso, Adv. Mater., 2001, 13, 11.

2 Y. Wang, A. S. Angelatos and F. Caruso, Chem. Mater., 2007, 20, 848.

3 L. Su, Y. Jing and Z. Zhou, Nanoscale, 2011, 3, 3967.

4 L. Luo, H. Yang, P. Yan, J. J. Travis, Y. Lee, N. Liu, D. M. Piper, S.-H. Lee, P. Zhao, S. M. George, J.-G. Zhang, Y. Cui, S. Zhang,

C. Ban and C.-M. Wang, ACS Nano, 2015, 9, 5559.

5 Y. Zhang, L. Jiang and C. Wang, Nanoscale, 2015, 7, 11940.

6 S. L. Yang, B. H. Zhou, M. Lei, L. P. Huang, J. Pan, W. Wu and H. B. Zhang, Chin. Chem. Lett., 2015, 26, 1293.

7 H. Zhang, Y. Dai, H. Zhang, W. Wang, Q. Huang, Y. Chen and L. Pu, Int. J. Electrochem. Sci., 2016, 11, 6279.

8 S. M. Abbas, S. T. Hussain, S. Ali, N. Ahmad, N. Ali and K. S. Munawar, Electrochim. Acta, 2013, 105, 481.

9 S. W. Oh, S. T. Myung, S. M. Oh, K. H. Oh, K. Amine, B. Scrosati and Y. K. Sun, Adv. Mater., 2010, 22, 4842.

10 L. Tan, L. Pan, C. Cao, B. Wang and L. Li, J. Power Sources, 2014, 253, 193.

11 Y. N. Jo, Y. Kim, J. S. Kim, J. H. Song, K. J. Kim, C. Y. Kwag, D. J. Lee, C. W. Park and Y. J. Kim, J. Power Sources, 2010, 195, 6031.

12 S. J. Park, Y. J. Kim and H. Lee, J. Power Sources, 2011, 196, 5133.

13 X. Y. Zhang, H. P. Li, X. L. Cui and Y. Lin, J. Mater. Chem., 2010, 20, 2801.

14 K. S. Raja, M. Misra, V. K. Mahajan, T. Gandhi, P. Pillai and S. K. Mohapatra, J. Power Sources, 2006, 161, 1450.

15 K. Xie, P. Wu, Y. Zhou, Y. Ye, H. Wang, Y. Tang and T. Lu, ACS Appl. Mater. Interfaces, 2014, 6, 10602.

16 P. Wu, N. Du, H. Zhang, J. Yu, Y. Qi and D. Yang, Nanoscale, 2011, 3, 746. 
17 H. Wang, P. Wu, H. Shi, F. Lou, Y. Tang, T. Zhou and T. Lu, Mater. Res. Bull., 2014, 55, 71.

18 A. H. Lu, T. Sun, W. C. Li, Q. Sun, F. Han, D. H. Liu and Y. Guo, Angew. Chem., Int. Ed., 2011, 50, 6799.

19 T. S. Sileika, D. G. Barrett, R. Zhang, K. H. A. Lau and P. B. Messersmith, Angew. Chem., Int. Ed., 2013, 52, 10766.

20 L. Pan, H. Wang, C. Wu, C. Liao and L. Li, ACS Appl. Mater. Interfaces, 2015, 7, 16003.

21 S. L. Cumberland and G. F. Strouse, Langmuir, 2002, 18, 269. 22 S. S. Shankar, A. Rai, A. Ahmad and M. Sastry, J. Colloid Interface Sci., 2004, 275, 496-502.

23 D. S. Sheny, J. Mathew and D. Philip, Spectrochim. Acta, Part A, 2011, 79, 254.

24 D. Philip and C. Unni, Phys. E, 2011, 43, 1318.

25 H. Lee, N. F. Scherer and P. B. Messersmith, Proc. Natl. Acad. Sci. U. S. A., 2006, 103, 12999.

26 E. McCafferty and J. P. Wightman, Surf. Interface Anal., 1998, 26, 549 .

27 B. Erdem, R. A. Hunsicker, G. W. Simmons, E. D. Sudol, V. L. Dimonie and M. S. El-Aasser, Langmuir, 2001, 17, 2664.

28 X. M. Wu, L. L. Wang, Y. Wang, J. S. Gu and H. Y. Yu, J. Membr. Sci., 2012, 421, 60.

29 R. Rodríguez, M. A. Blesa and A. E. Regazzoni, J. Colloid Interface Sci., 1996, 177, 122.
30 J. L. Dalsin, L. Lin, S. Tosatti, J. Vörös and M. Textor, Langmuir, 2005, 21, 640.

31 M. L. Terranova, S. Orlanducci, E. Tamburri, V. Guglielmotti and M. Rossi, J. Power Sources, 2014, 246, 167.

32 W. Li, Y. Tang, W. Kang, Z. Zhang, X. Yang, Y. Zhu and C. S. Lee, Small, 2015, 11, 1345.

33 S. Yang, X. Feng, L. Zhi, Q. Cao, J. Maier and K. Müllen, Adv. Mater., 2010, 22, 838.

34 D. Ji, Y. Wan, Z. Yang, C. Li, G. Xiong, L. Li and H. Luo, Electrochim. Acta, 2016, 192, 22.

35 J. Li, J. Wang, J. Yang, X. Ma and S. Lu, J. Alloys Compd., 2016, 688, 1072.

36 X. Li, P. Meduri, X. Chen, W. Qi, M. H. Engelhard, W. Xu and J. G. Zhang, J. Mater. Chem., 2012, 2, 11014.

37 G. N. Zhu, Y. G. Wang and Y. Y. Xia, Energy Environ. Sci., 2012, 5, 6652.

38 Z. Yang, D. Choi, S. Kerisit, K. M. Rosso, D. Wang, J. Zhang, G. Graff and J. Liu, J. Power Sources, 2009, 192, 588.

39 J. Wang, L. Shen, H. Li, X. Wang, P. Nie, B. Ding and X. Zhang, Electrochim. Acta, 2014, 133, 209.

40 Y. Chen, X. Ma, X. Cui and Z. Jiang, J. Power Sources, 2016, 302, 233.

41 Q. Cao, H. P. Zhang, G. J. Wang, Q. Xia, Y. P. Wu and H. Q. Wu, Electrochem. Commun., 2007, 9, 1228. 